\title{
High Humidity Aerodynamic Effects Study on Offshore Wind Turbine Airfoil/Blade Performance through CFD Analysis
}

\author{
Weipeng Yue, ${ }^{1,2}$ Yu Xue, ${ }^{3}$ and Yan Liu $^{3}$ \\ ${ }^{1}$ School of Energy, Power and Mechanical Engineering, North China Electric Power University, Changping District, \\ Beijing 102206, China \\ ${ }^{2}$ Zhangjiakou Wind and Solar Power Energy Demonstration Station Co., Ltd., State Grid Xin Yuan Company, \\ Zhangjiakou 075000, China \\ ${ }^{3}$ China Datang Corporation Science and Technology Research Institute, Changping District, Beijing 102206, China \\ Correspondence should be addressed to Yan Liu; 1112102023@ncepu.edu.cn
}

Received 8 January 2017; Accepted 28 February 2017; Published 30 March 2017

Academic Editor: Yutaka Ohta

Copyright (C) 2017 Weipeng Yue et al. This is an open access article distributed under the Creative Commons Attribution License, which permits unrestricted use, distribution, and reproduction in any medium, provided the original work is properly cited.

\begin{abstract}
Damp air with high humidity combined with foggy, rainy weather, and icing in winter weather often is found to cause turbine performance degradation, and it is more concerned with offshore wind farm development. To address and understand the high humidity effects on wind turbine performance, our study has been conducted with spread sheet analysis on damp air properties investigation for air density and viscosity; then CFD modeling study using Fluent was carried out on airfoil and blade aerodynamic performance effects due to water vapor partial pressure of mixing flow and water condensation around leading edge and trailing edge of airfoil. It is found that the high humidity effects with water vapor mixing flow and water condensation thin film around airfoil may have insignificant effect directly on airfoil/blade performance; however, the indirect effects such as blade contamination and icing due to the water condensation may have significant effects on turbine performance degradation. Also it is that found the foggy weather with microwater droplet (including rainy weather) may cause higher drag that lead to turbine performance degradation. It is found that, at high temperature, the high humidity effect on air density cannot be ignored for annual energy production calculation. The blade contamination and icing phenomenon need to be further investigated in the next study.
\end{abstract}

\section{Introduction}

In recent years, there has been an increase in large offshore wind installations to harness the huge potential that wind energy offers off the coasts of the China. While offshore wind resources are abundant, stronger, and blow more consistently than land-based wind resources, offshore wind turbines are often operated in high humidity environment; however, our wind turbine power curve IEC standard measurements are measured onshore and often much low to mid humidity environment; also the wind shear data from offshore wind may be different from onshore; what do these factors mean to wind turbine performance needs to be addressed as the offshore wind energy projects are evaluated for annual energy production (AEP) calculation. When air contains high water vapor for the offshore high humidity condition, the condensation may happen at rotating blade surface, which may cause the blade performance degradation due to contamination or icing during winter weather, as show in Figure 1. Also in the morning, the foggy weather (or rainy day) may often happen around offshore wind farm, in which the air is mixed with water droplets in micrometer scale; when they impinge with rotating blade, this may also cause higher drag, thus having an impact on turbine performance. With greater potential for corrosion from exposure to seawater and high humidity, offshore wind turbines must be designed more robustly (i.e., requiring less maintenance) than land-based turbines due to the high costs of transporting maintenance crews and replacement components to and from offshore wind plant sites, which are the other factors we have to address.

In this paper, however, we will focus on analyzing the humidity aerodynamic effects in terms of air density and wind turbine airfoil/blade/rotor performance; we will further investigate water condensation effects on wind turbine blade 


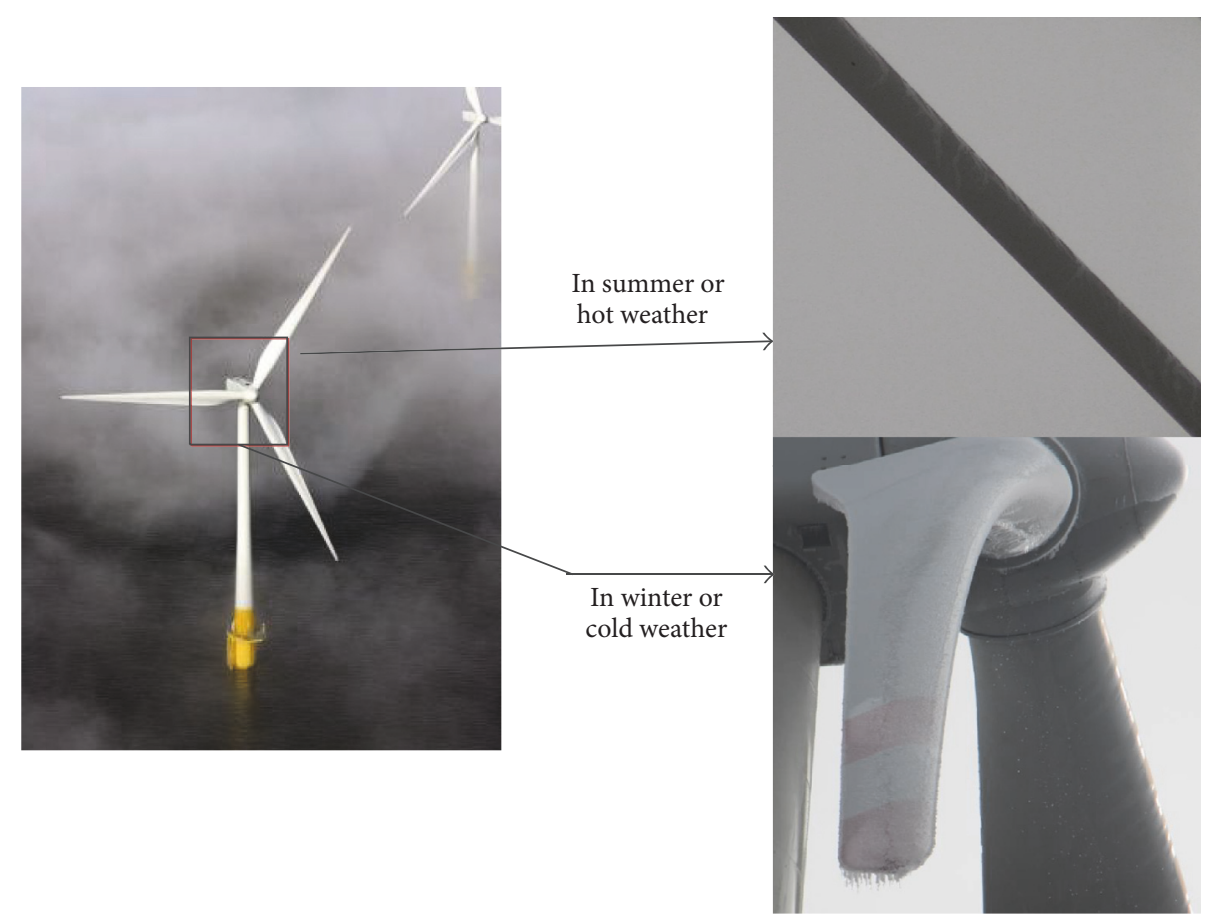

FIGURE 1: Offshore wind turbines shrouded in foggy and water film on blade surface and icing on blade surface.

using CFD analysis, as the water condensation and droplet thin firm formation often cause the result of blade contamination and icing formation in the winter, that cause turbine performance degradation. The wind shear data of offshore wind and corrosion issue are not included in this paper.

\section{Spreadsheet Aerodynamic Density Effect of Damp Air}

Wind is a form of solar energy and is a result of the uneven heating of the atmosphere by the sun, the irregularities of earth's surface, and the rotation of the earth. The terms wind energy and wind power describe the process by which the wind is used to generate mechanical power or electricity. Wind turbines convert the kinetic energy in the wind into mechanical power.

This mechanical power can be used for specific tasks or a generator can convert this mechanical power into electricity. The most popular modern wind turbines are horizontalaxis wind turbines which typically have either two blades or three blades. These three-bladed wind turbines are operated "upwind," with the blades facing into the wind. Larger wind turbines are more cost effective and are grouped together into wind farms, which provide bulk power to the electrical grid. The power of wind turbine generated can be calculated as follows:

$$
\text { Power }=\frac{1}{2} \rho A v^{3} C_{p}(\lambda, \beta),
$$

where the wind power is directly proportional to the density of air and the aerodynamic coefficient of wind turbine rotor. Table 1 was computed from Barani Air Density Calculator where it shows that humidity (quantified as relative humidity $(\mathrm{RH})$ in percentage) effect on air density can be ranging from 0.57 to $1.92 \%$ depending on temperature and thus the same effect on power. Relative humidity is the ratio of the partial pressure of water vapor to the equilibrium vapor pressure of water at a given temperature.

We take one offshore wind project as an example from southern east China. As the first-order effect, the average temperature is 20 degrees $\mathrm{C}$ and average humidity is $80 \% \mathrm{RH}$; the effect on power will be $0.41 \%(0.66 \%-0.25 \%$ from Table 1$)$, less power than standard power evaluated at $25 \% \mathrm{RH}$. If the wind farm power is $200 \mathrm{MW}$ powered by $4 \mathrm{MW}$ turbine, the power lost due to high humidity is about $4,500,000 \mathrm{kWh}$ per year from theoretical calculation, which is considerable.

In the next sessions, we will study the high humidity effects on wind turbine aerodynamic coefficient, through analyzing the aerodynamic effects on airfoil and blade using CFD method.

\section{Airfoil CFD Modeling Study of High Humidity Effects}

For the airfoil modeling study, we utilized Fluent CFD analysis following 2D mesh as shown in Figure 2 of a typical airfoil NACA63418 to start with species transport model and film condensation model and then $3 \mathrm{D}$ airfoil modeling with Eulerian Wall Film (EWF) model. We use Fluent species transport model without reactions to solve water vapor and air mixing flow around airfoil and then film condensation Fluent User-Defined Function (UDF) model to study the water film formation around airfoil. Last, we use multiphase 
TABLE 1: Air density versus air relative humidity and its effect on power.

\begin{tabular}{|c|c|c|c|c|c|}
\hline Temperature $\left({ }^{\circ} \mathrm{C}\right)$ & Humidity (-\%) & Dry air density $\left(\mathrm{kg} / \mathrm{m}^{3}\right)$ & Effect on power (-\%) & Moist air density $\left(\mathrm{kg} / \mathrm{m}^{3}\right)$ & Effect on power (-\%) \\
\hline \multirow{4}{*}{15} & 25 & \multirow{4}{*}{1.225} & \multirow{4}{*}{0.0} & 1.223 & 0.16 \\
\hline & 50 & & & 1.221 & 0.33 \\
\hline & 70 & & & 1.22 & 0.41 \\
\hline & 90 & & & 1.218 & 0.57 \\
\hline \multirow{4}{*}{20} & 25 & \multirow{4}{*}{1.204} & \multirow{4}{*}{1.71} & 1.201 & 0.25 \\
\hline & 50 & & & 1.199 & 0.42 \\
\hline & 70 & & & 1.197 & 0.58 \\
\hline & 90 & & & 1.195 & 0.75 \\
\hline \multirow{4}{*}{25} & 25 & \multirow{4}{*}{1.184} & \multirow{4}{*}{3.35} & 1.18 & 0.34 \\
\hline & 50 & & & 1.177 & 0.59 \\
\hline & 70 & & & 1.174 & 0.84 \\
\hline & 90 & & & 1.171 & 1.10 \\
\hline \multirow{4}{*}{30} & 25 & \multirow{4}{*}{1.164} & \multirow{4}{*}{4.98} & 1.16 & 0.34 \\
\hline & 60 & & & 1.153 & 0.95 \\
\hline & 70 & & & 1.151 & 1.12 \\
\hline & 90 & & & 1.148 & 1.37 \\
\hline \multirow{4}{*}{35} & 25 & \multirow{4}{*}{1.146} & \multirow{4}{*}{6.45} & 1.139 & 0.61 \\
\hline & 50 & & & 1.133 & 1.13 \\
\hline & 70 & & & 1.129 & 1.48 \\
\hline & 90 & & & 1.124 & 1.92 \\
\hline
\end{tabular}

Reference is Barani Air Density Calculator as atmosphere pressure assumed to be the same.

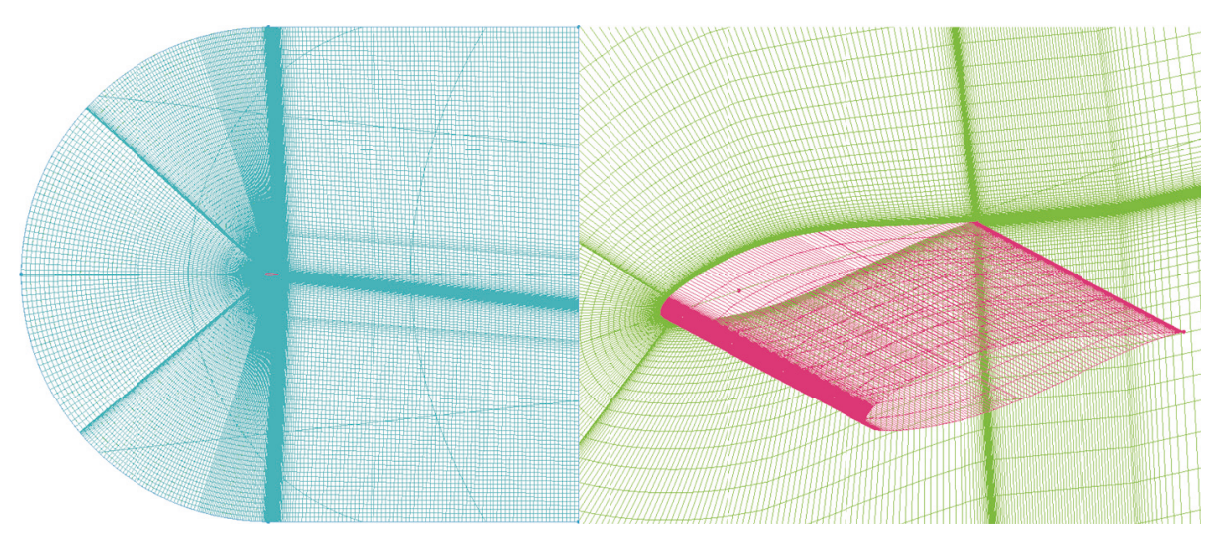

FIGURE 2: 2D and 3D airfoil mesh of NACA63418.

Eulerian model with film accretion to solve water droplet and air mixing flow around 3D airfoil.

3.1. Species Transport Model. The mixing and transport of the air water vapor mixture were modeled by solving the conservation equations for every species individually, within a phase [1]. The number of phases depends on the way volumetric condensation is treated, which is described in the following equations. A mixture template of air and water vapor was defined with respective material properties. An incompressible ideal gas approximation was used to calculate mixture density. The diffusion energy source for the species equations was considered as shown below, as diffusion might be significant in the low speed near-wall region.
The governing equations are the equations of conservation of mass, momentum, and energy and are written as in [1-4]:

Overall mass is

$$
\frac{\partial}{\partial t}(\rho)+\nabla(\rho U)=0
$$

Momentum is

$$
\frac{\partial}{\partial t}(\rho U)+\nabla(\rho U U)=-\nabla p+\nabla \tau+\rho B .
$$

Energy is

$$
\frac{\partial}{\partial t}(\rho h)+\nabla(\rho U h)=-\nabla q+\dot{S}_{h}
$$




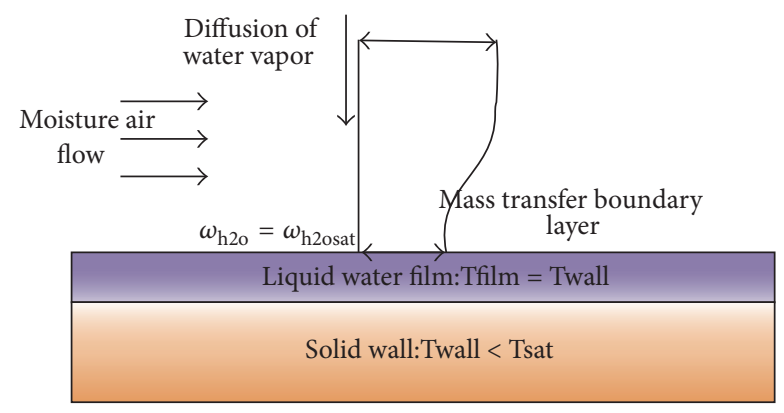

FIgURE 3: Schematic of the condensation model [3].

Species mass is

$$
\frac{\partial}{\partial t}\left(\rho Y_{i}\right)+\nabla \cdot\left(\rho U Y_{i}\right)=-\nabla \cdot \vec{J}_{i}
$$

where $\rho$ is the mixture density, $p$ is the pressure, $\tau$ is the shear stress tensor, and $B$ is the body force vector. In (4), $\dot{S}_{h}$ represents the net source due to viscous dissipation and other work and heat interactions and $q$ denotes the net heat flux due to molecular conduction, radiation, and interspecies diffusion.

In (5), $Y_{i}$ is the local mass fraction of each species. $\vec{J}_{i}$ is mass diffusion in turbulent flows in the following form:

$$
\vec{J}_{i}=-\left(\rho D_{i, m}+\frac{\mu_{t}}{\mathrm{Sc}_{t}}\right) \nabla Y_{i},
$$

where $\mathrm{Sc}_{t}$ is the turbulent Schmidt number, $\mu_{t}$ is the turbulent viscosity, and $D_{i, m}$ is the mass diffusion coefficient for species $i$ in the mixture.

The species transport model is best utilized to analyze the aerodynamic effects from mixing air with water vapor without condensation and droplet formation happen.

3.2. Film Condensation Model. When water condensation happens with thin film formation around airfoil, the model for wall condensation is required with the work adopted from the study of Bell (2003) [2] for condensation of superheated water on cold flat plate. It is conceptualized that condensation occurs as water vapor diffuses through the mass transfer boundary layer at the surface and, on contact with the cold surface, releases the latent heat to form a liquid film of water. The liquid film attains the wall temperature and the vapor diffusion and condensation continue at the liquid film-gas phase (air-vapor mixture) interface. This process is shown schematically in Figure 3.

A User-Defined Function (UDF) in Fluent has been developed to predict the condensation rate for a mixture of air and water vapor flowing past a specified temperature surface. The effect of the condensation process on the flow and species distribution in the vapor phase is incorporated into the flow calculations through a customized source term applied in wall-adjacent cells [3]. The model on which the UDF is based contains several assumptions as follows:

(1) Vapor phase contains a binary ideal gas mixture of air and water vapor.
TABLE 2: Material properties for water vapor condensation UDF [11, 12].

\begin{tabular}{lcc}
\hline \multirow{2}{*}{ Mixture property of damp air } & \multicolumn{2}{c}{ Relative humidity } \\
& $25 \%$ & $90 \%$ \\
\hline Thermal conductivity $[\mathrm{W} /(\mathrm{m} \cdot \mathrm{K})]$ & 0.0264 & 0.0264 \\
Viscosity $[\mathrm{kg} /(\mathrm{m} \cdot \mathrm{s})]$ & $1.86 \times 10^{-5}$ & $1.86 \times 10^{-5}$ \\
Mass diffusivity $\left[\mathrm{m}^{2} / \mathrm{s}\right]$ & $2.595 \times 10^{-5}$ & $2.595 \times 10^{-5}$ \\
Specific heat $[\mathrm{J} /(\mathrm{kg} \cdot \mathrm{K})]$ & 1010.526 & 1025.104 \\
Absolute humidity $\left[\mathrm{kg} / \mathrm{m}^{3}\right]$ & 0.0057477 & 0.027254 \\
Density $\left[\mathrm{kg} / \mathrm{m}^{3}\right)$ & 1.16 & 1.148 \\
Dew point $\left[{ }^{\circ} \mathrm{C}\right]$ & 7.8 & 28.2 \\
\hline
\end{tabular}

(2) The liquid phase consists of only water.

(3) Local thermodynamic equilibrium exists at the liquid-vapor interface.

(4) Film condensation only is considered. Dropwise condensation does not take place.

(5) The thermal resistance of the liquid film is neglected.

As a consequence of the assumptions on which the model is based, the condensation rate is governed by the rate of diffusion of water vapor towards the cold surface. This allows the condensation rate at the liquid vapor interface to be predicted as follows. Species mass fluxes for air and water vapor at the liquid-vapor interface can be written as follows (Bird et al., 1960 [4]):

$$
\dot{m}_{\mathrm{h}_{2} \mathrm{o}}^{\prime \prime}=\rho \omega_{\mathrm{h}_{2} \mathrm{o}} v-\rho D \frac{\partial \omega_{\mathrm{h}_{2} \mathrm{o}}}{\partial n},
$$

where $\dot{m}^{\prime \prime}$ is condensation mass flux $\left(\mathrm{kg} / \mathrm{m}^{2} \cdot \mathrm{s}\right)$. In the UDF, condensation is assumed to take place if the wall temperature is less than or equal to the saturation temperature corresponding to the partial pressure of water vapor at the surface. If the temperature is above the saturation temperature, the water vapor mass fraction is set to a value equal to the value in the wal- adjacent cell. In order to satisfy Assumption (3), if the temperature is less than or equal to the saturation temperature, the water vapor mass fraction at the wall used to represent the liquid-vapor interface is assigned a value such that the partial pressure of the water vapor equals the saturation pressure for water at the local wall temperature as follows:

$$
\begin{aligned}
\dot{m}^{\prime \prime \prime} & =\frac{\dot{m}_{\mathrm{h}_{2} \mathrm{o}}^{\prime \prime \prime}}{\omega_{\mathrm{h}_{2} \mathrm{o}}} \\
\dot{m}_{\mathrm{h}_{2} \mathrm{o}}^{\prime \prime \prime} & =\frac{\omega_{\mathrm{h}_{2} \mathrm{o}}}{\left(\omega_{\mathrm{h}_{2} \mathrm{o}}-1\right)} \rho D \frac{\partial \omega_{\mathrm{h}_{2} \mathrm{o}}}{\partial n} \frac{A_{\text {cell wall }}}{V_{\text {cell }}},
\end{aligned}
$$

where $\dot{m}^{\prime \prime \prime}$ is volumetric mass source $\left(\mathrm{kg} / \mathrm{m}^{3} \cdot \mathrm{s}\right)$. Equations (8) are used as a source terms within the source code of the UDF (Table 2).

3.3. Eulerian Wall Film. The Fluent Eulerian Wall Film (EWF) model can be used to predict the creation and flow of thin liquid films on the surface of walls [5]. 
In EWF model, the film is not resolved using mesh normal to the surface; instead this model uses a virtual film on the surface so the film does not affect the core flow momentum field. In many cases, you would be interested in modeling a thin film flow which can separate, strip, and evaporate but does not affect the core flow field. This kind of thin film modeling is computationally expensive in general multiphase framework where you will need very fine mesh to model the film and also need to calculate interphase flux accurately. EWF model can only be used with 3D solver and EWF model assumes that film always flows parallel to the surface so normal component of film velocity is zero. The film is assumed to have a parabolic velocity profile and bilinear temperature profile across its depth.

Conservation of mass for a two-dimensional film in a three-dimensional domain is

$$
\frac{\partial h}{\partial t}+\nabla_{s}\left[h \vec{V}_{l}\right]=\frac{\dot{m}_{s}}{\rho_{l}},
$$

where $\rho$ is the liquid density, $h$ the film height, $\nabla_{s}$ the surface gradient operator, $V_{l}$ the mean film velocity, and $\dot{m}_{s}$ the mass source per unit wall area due to water droplet collection.

Conservation of film momentum is given as follows:

$$
\begin{aligned}
\frac{\partial h \vec{V}_{l}}{\partial t}+\nabla_{s} \cdot\left(h \vec{V}_{l} \vec{V}_{l}\right)= & -\frac{h \nabla_{s} P_{L}}{\rho_{l}}+\left(\vec{g}_{\tau}\right) h+\frac{3}{2 \rho_{l}} \vec{\tau}_{f s} \\
& -\frac{3 v_{l}}{h} \vec{V}_{l}+\frac{\dot{q}}{\rho_{l}}
\end{aligned}
$$

where

$$
\begin{aligned}
& P_{L}=P_{\text {gas }}+P_{h}+P_{\sigma} \\
& P_{h}=-\rho h(\vec{n} \cdot \vec{g}) \\
& P_{\sigma}=-\sigma \nabla_{s} \cdot\left(\nabla_{s} h\right) .
\end{aligned}
$$

In an Eulerian multiphase flow, the secondary phase to be collected on a solid surface must have the same material as defined in the Eulerian Wall Film model. When the secondary phase is captured by the wall surface, its mass and momentum are removed from the multiphase flow and added as source terms to the continuity and momentum equations, respectively, of the wall film.

The mass source term is given by $\dot{m}_{s}=\alpha_{d} \rho_{d} V_{d n} A$, where $\alpha$ is the secondary phase volume fraction, $\rho_{d}$ is the secondary phase density, $V_{d n}$ is the phase velocity normal to the wall surface, and $A$ is the wall surface area. The momentum source is given by $\dot{\vec{q}}_{s}=\dot{m}_{s} \cdot \vec{V}_{d}$, where $\vec{V}_{d}$ is the secondary phase velocity vector.

The collection efficiency $(\beta)$ is calculated as the ratio of the amount or mass of water collected on the surface to the total mass of droplets being injected at the inlet. Eulerian methods can be used to determine the collection efficiency.

Collection efficiency is defined as

$$
\beta=\frac{\dot{m}_{p}}{\left(L_{\mathrm{WC}} * V\right)},
$$

where $\dot{m}_{p}$ is the impingement mass flux, that is, the flow rate of the particle stream impinging on the face and is given by $\dot{m}_{p}=\alpha_{d} \rho_{d} V_{d n} A . L_{\mathrm{WC}}$ is the far-field liquid water content $\left(\mathrm{kg} / \mathrm{m}^{3}\right)$ and $V$, the phase velocity, is the far-field flow velocity $(\mathrm{m} / \mathrm{s})$. In the calculation of collection efficiency, these values are used as reference values only and do not affect the flow field in any way. At least one iteration is required to do collection efficiency calculation. Easily specifying dropletfree stream condition and smooth impingement region can be achieved. Each droplet size as a separated phase with one set of transport equation can be solved.

It is always good to first achieve a converged multiphase flow solution and then solve for Eulerian Wall Film. It is always good to start with a smaller film time-step size. So, for steady-state calculations, we select the Adaptive Time Stepping option to set the Max. Courant Number and the Initial Time Step (the Eulerian Wall Film model is always transient).

3.4. Solution Method and Results. A variety of spatial and temporal discretization schemes and turbulent models are also available in Fluent. For the present simulations, the pressure-based solver was chosen, as the flow can be considered to be in the incompressible fluid. The full threedimensional Navier-Stokes equations were solved using a steady, implicit approach. The Semi-Implicit Pressure Linked Equations-Consistent (SIMPLEC) algorithm 2 in [6] was used to treat pressure-velocity coupling for stability. The third-order Monotone Upstream-Centered Schemes for Conservation Laws (MUSCL) were used to derive the face values of different variables for the spatial discretization, which were used to compute the convective fluxes. The RhieChow scheme 3 in [6] was selected to interpolate pressure at the control volume face and to satisfy the mass conservation without pressure oscillations. For simulating turbulence, the shear stress transport (SST) $k$ - $\omega$ model was used.

The aerodynamic results of lift and drag coefficient are summarized in Table 3. Through the comparison of two different models of moisture and humidity at RH $25 \%$ and RH $90 \%$ of the lift coefficient, drag coefficient, and lift drag ratio, it was found that, in the species transport model and VF model, $25 \%$ air humidity of the lift to drag ratio is higher than $90 \%$ humidity, and lift coefficient and drag coefficient curve are not exactly the same; difference comparison between the two found that numerical difference is very small (usually less than $1 \%$ ), considering that the numerical calculation error can be due to moisture changes on the lift and drag coefficient of little effect.

The lift coefficient calculated by the Eulerian Wall Film model for foggy weather condition is smaller than that calculated by other models, and the drag coefficient is significantly larger than that of the other models, which leads to a significant reduction in the lift drag ratio. It can be seen that, with the increase of humidity, the lift coefficient decreases, the drag coefficient increases, and the lift drag ratio decreases. The similar results were shown with heavy rain fall study from [7-10]. Because the drag coefficient is larger than other models, there may be some uncertainties; 
TABLE 3: Airfoil performance with various condensation models for $\mathrm{Re}=3 \times 10^{6}, \mathrm{AOA}=6$ degrees.

\begin{tabular}{|c|c|c|c|c|c|}
\hline Model & $\mathrm{RH}(\%)$ & $\mathrm{Cl}$ & $\mathrm{Cd}$ & $\mathrm{L} / \mathrm{D}$ & Condensation mass flux $\left(\mathrm{kg} /\left(\mathrm{m}^{2} \cdot \mathrm{s}\right)\right)$ \\
\hline \multirow{2}{*}{ Species transport (2D mesh) } & 25 & 0.98535 & 0.01353 & 72.84859 & \\
\hline & 90 & 0.97485 & 0.01341 & 72.69575 & \\
\hline \multirow{2}{*}{$\begin{array}{l}\text { Vapor film (VF) condensation } \\
\text { model ( } 2 \mathrm{D} \text { mesh) }\end{array}$} & 25 & 0.98535 & 0.01353 & 72.85397 & \\
\hline & 90 & 0.97484 & 0.01341 & 72.70043 & \\
\hline \multirow{2}{*}{$\begin{array}{l}\text { VF model (temperature } \\
\text { difference }=5^{\circ} \mathrm{C} \text { ) }\end{array}$} & 25 & 0.98539 & 0.01353 & 72.85155 & -0.01296 \\
\hline & 90 & 0.97533 & 0.01341 & 72.74239 & -0.17910 \\
\hline \multirow{2}{*}{$\begin{array}{l}\text { VF model (temperature } \\
\left.\text { difference }=10^{\circ} \mathrm{C}\right)\end{array}$} & 25 & 0.98558 & 0.01353 & 72.87098 & -0.08224 \\
\hline & 90 & 0.97603 & 0.01341 & 72.80546 & -0.43686 \\
\hline \multirow{2}{*}{ Species transport (3D mesh) } & 25 & 0.97877 & 0.01413 & 69.28855 & \\
\hline & 90 & 0.97839 & 0.01416 & 69.10998 & \\
\hline \multirow{2}{*}{$\begin{array}{l}\text { Vapor film (VF) condensation } \\
\text { model (3D mesh) }\end{array}$} & 25 & 0.97860 & 0.01414 & 69.22261 & \\
\hline & 90 & 0.97832 & 0.01416 & 69.07576 & \\
\hline \multirow{2}{*}{$\begin{array}{l}\text { VF model }(3 \mathrm{D} \text {-temperature } \\
\left.\text { difference }=5^{\circ} \mathrm{C}\right)\end{array}$} & 25 & 0.98018 & 0.01392 & 70.41523 & -0.14498 \\
\hline & 90 & 0.98028 & 0.01396 & 70.24579 & -3.12070 \\
\hline \multirow{2}{*}{$\begin{array}{l}\text { VF model }(3 \mathrm{D} \text {-temperature } \\
\left.\text { difference }=10^{\circ} \mathrm{C}\right)\end{array}$} & 25 & 0.97837 & 0.01381 & 70.87070 & -0.91603 \\
\hline & 90 & 0.97956 & 0.01386 & 70.69573 & -5.72690 \\
\hline \multirow{3}{*}{$\begin{array}{l}\text { Eulerian Wall Film (EWF 3D } \\
\text { mesh) }\end{array}$} & 0 & 0.94552 & 0.02873 & 32.91512 & \\
\hline & 25 & 0.94494 & 0.02909 & 32.47886 & \\
\hline & 90 & 0.92906 & 0.03017 & 30.79417 & \\
\hline
\end{tabular}

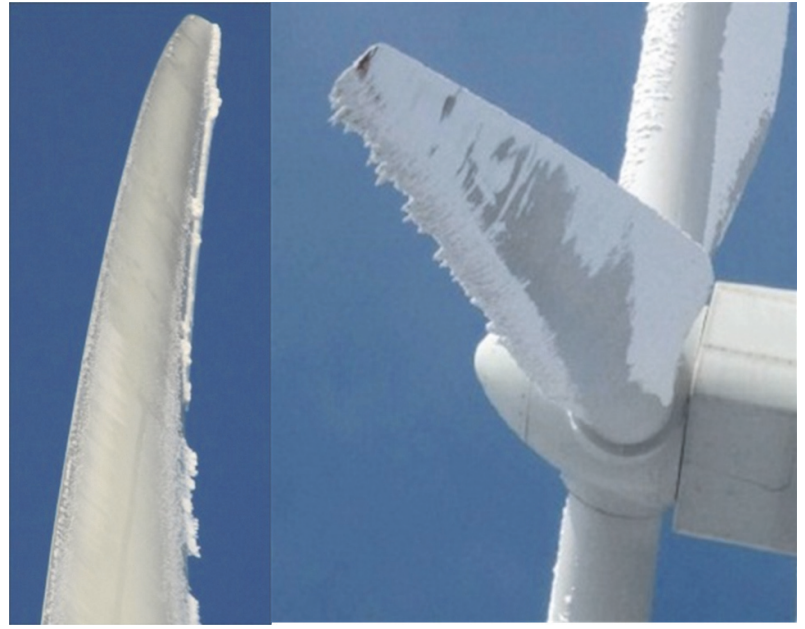

FIGURE 4: Ice on turbine blade $[13,14]$.

so this paper is mainly to study the condensation distribution on the surface of the airfoil by the Euler wall model. The condensation of water vapor and the impact of droplets on the surface of an airfoil or a blade can lead to other consequences of aerodynamic degradation, such as blade contamination and icing as shown in Figures 4 and 5.

When the condensation model is used, it is found that when the temperature difference between the damp air and airfoil surfaces becomes larger, the water mass flow rate of the airfoil surface is larger, and when the humidity is higher, the condition is more obvious. But around airfoil, Figure 6 shows

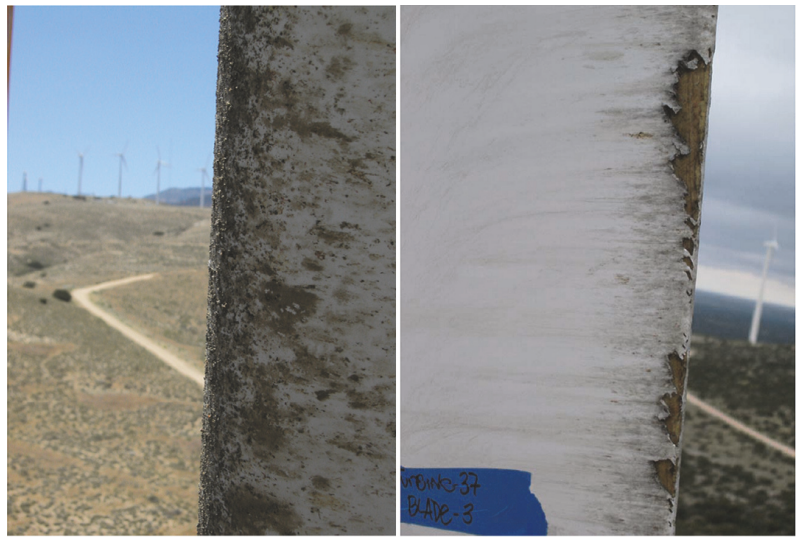

Figure 5: Blade contamination and erosion $[15,16]$.

the higher temperature difference and the more condensation mass flow rate curve have a similar shape as pressure curve occurs. With different humidities, airfoil surface pressure coefficient curves remained basically unchanged. Airfoil surface condensation cloud mass flow rate can be found as shown in Figure 7 that the condensate mass flow rate larger region at the leading edge and the trailing edge region, mainly airfoil leading edge surface and the upper surface of the trailing edge, so, in the actual wind turbine operation, it would be the region due to the presence of surface water condensation, is more likely to cause contamination on the surface of (insects, such as particles) adhesion as shown in Figure 8. 


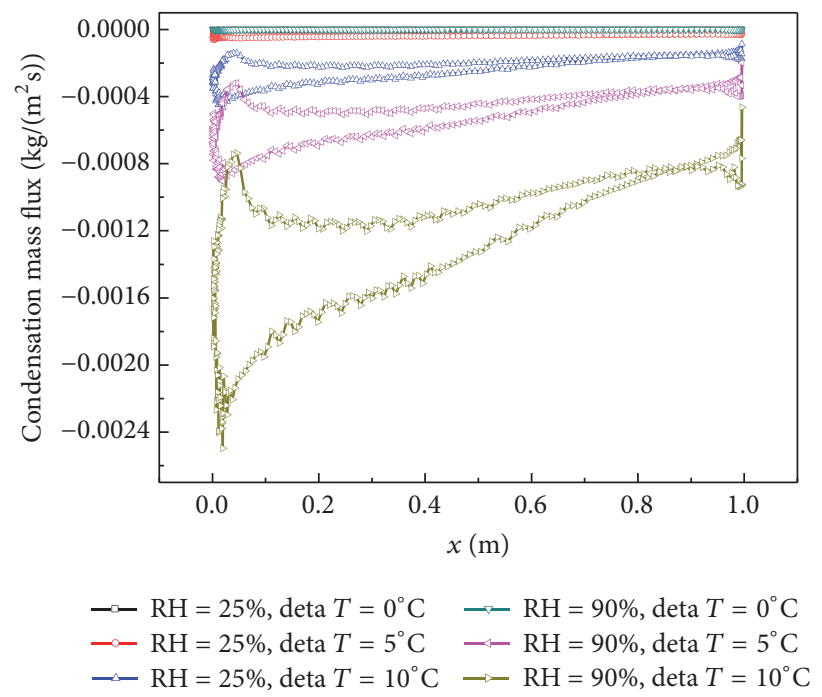

FIGURE 6: Condensation mass flux around airfoil for $\mathrm{RH}=25 \%$ and $\mathrm{RH}=90 \%$ using VF model.

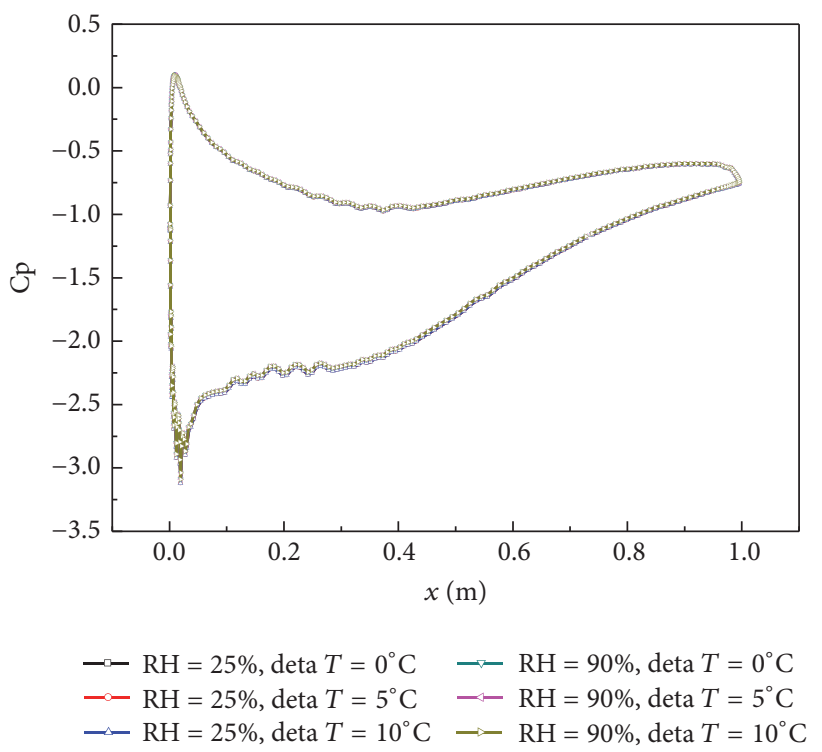

FIgURE 7: Pressure coefficient around airfoil for $\mathrm{RH}=25 \%$ and $\mathrm{RH}=90 \%$ using VF model.

Figure 9 shows the approximate separation point air velocity vector diagram of the different height and various working conditions of the Eulerian Wall Film model. A crosssectional comparison of different wind speed, temperature, humidity, and velocity vector found the same temperature and wind speed and humidity $90 \%$ compared with $25 \%$ humidity premature separation; when humidity is higher, separation is stronger and position is closer to the front, which more easily leads to separation.

Figure 10 shows the flow pattern and water vapor condensation area at leading edge and some at trailing edge of airfoil. Figure 11 shows that RH 90\% condition has much higher water film thickness in comparison with RH $25 \%$ condition and high angle of attack (AOA) has more water condensation in the range of $70 \mu \mathrm{m}$ water film thickness. Figure 12 shows that the EWF modeling is transient and the water condensation film thickness changes with time.

Figures 13 and 14 are corresponding for water vapor condensation in terms of water film thickness around airfoil for both $\mathrm{AOA}=6$ and 10 degrees, both showing the airfoil surface water content analysis; it is found that the water condense most in front of the airfoil near the leading edge but much less near the trailing edge. And it is found that the negative pressure side has more water condensation than pressure side, while the $\mathrm{AOA}=10$ degrees is much significant than $\mathrm{AOA}=6$ degrees.

Table 4 summarized the RH effects at different AOA for $\mathrm{Cl}, \mathrm{Cd}$, water volume fraction, sum of water condensation film, and water film thickness. 
TABLE 4: Value of EWF model on 1200 steps.

\begin{tabular}{ccccccc}
\hline AOA $\left({ }^{\circ}\right)$ & $\mathrm{RH}(\%)$ & $\mathrm{Cl}$ & $\mathrm{Cd}$ & $\begin{array}{c}\text { Water liquid Eulerian } \\
\text { volume fraction } \\
{\left[\times 10^{-6}\right]}\end{array}$ & $\begin{array}{c}\text { Sum of film mass on } \\
\text { airfoil }[\mathrm{kg}]\end{array}$ & $\begin{array}{c}\text { Sum of film thickness } \\
\text { on airfoil }[\mathrm{m}]\end{array}$ \\
\hline 6 & 25 & 0.94505 & 0.029097 & 0.4946 & 0.012173075 & 0.06826515 \\
& 90 & 0.92920 & 0.030178 & 0.4469 & 0.014304958 & 0.082225235 \\
10 & 25 & 1.2552 & 0.049594 & 1.339 & 0.009355492 & 0.025474465 \\
& 90 & 1.2221 & 0.051778 & 0.552 & 0.015545382 & 0.043205235 \\
\hline
\end{tabular}

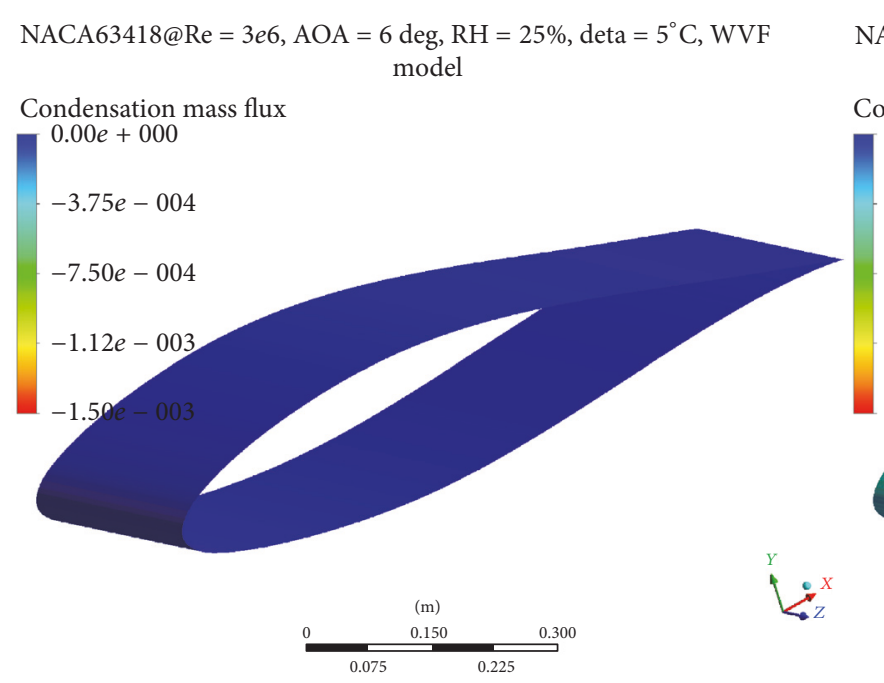

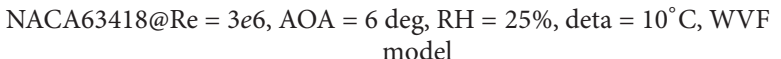

Condensation mass flux

$0.00 e+000$
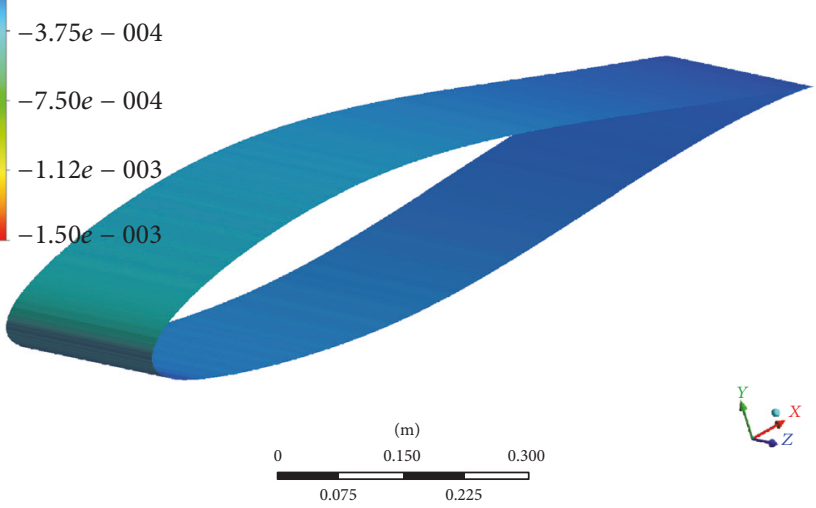

$\mathrm{NACA} 63418 @ \mathrm{Re}=3 e 6, \mathrm{AOA}=6 \mathrm{deg}, \mathrm{RH}=90 \%$, deta $=10^{\circ} \mathrm{C}, \mathrm{WVF}$ model

Condensation mass flux

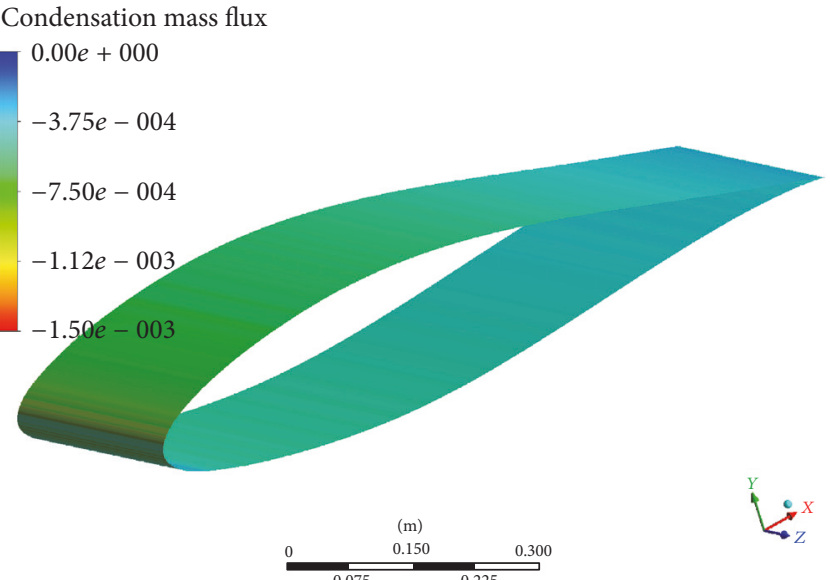

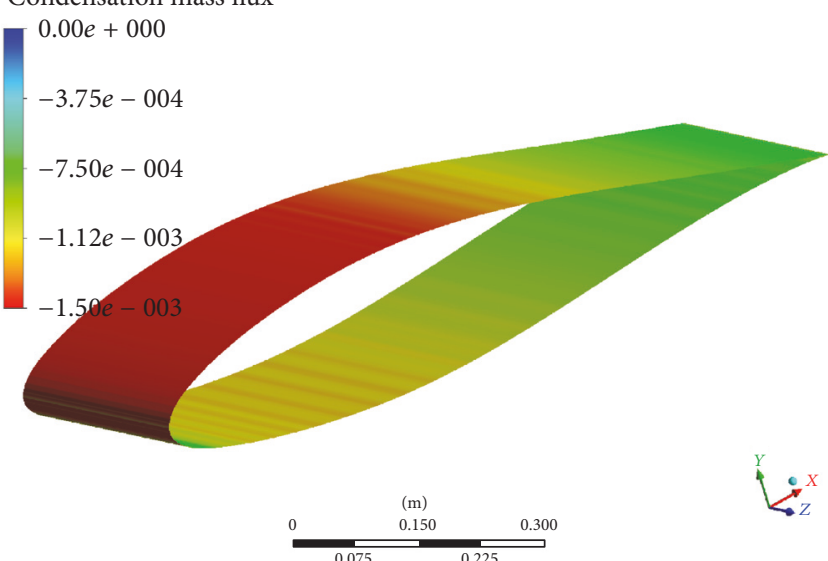

Figure 8: Contour plots of condensation mass flux on airfoil using 3D VF model.

In general, through on airfoil surface wet air flow analysis, it is found that the moisture of airfoil dynamic performance impact is small; the moisture effects on airfoil are mainly moisture in the airfoil surface condensation or convergence, that is easy to cause pollution of adhesion. By analyzing the water vapor condensation on the airfoil surface and the distribution of the surface water film, it provides reference for the understanding airfoil degradation because water condensation can lead to blade icing and contamination.

\section{Rotating Blade CFD Modeling Study of High Humidity Effect}

4.1. Result Analysis Based on Film Condensation Model. Like airfoil study, we also utilized Fluent CFD analysis; to study the effect of humidity on blade performance, used two models, species transport and film condensation UDF as stated above.

Computation using a typical $1.5 \mathrm{MW}$ blade model, for three-blade rotor, considers the 120 -degree rotation cycle; 

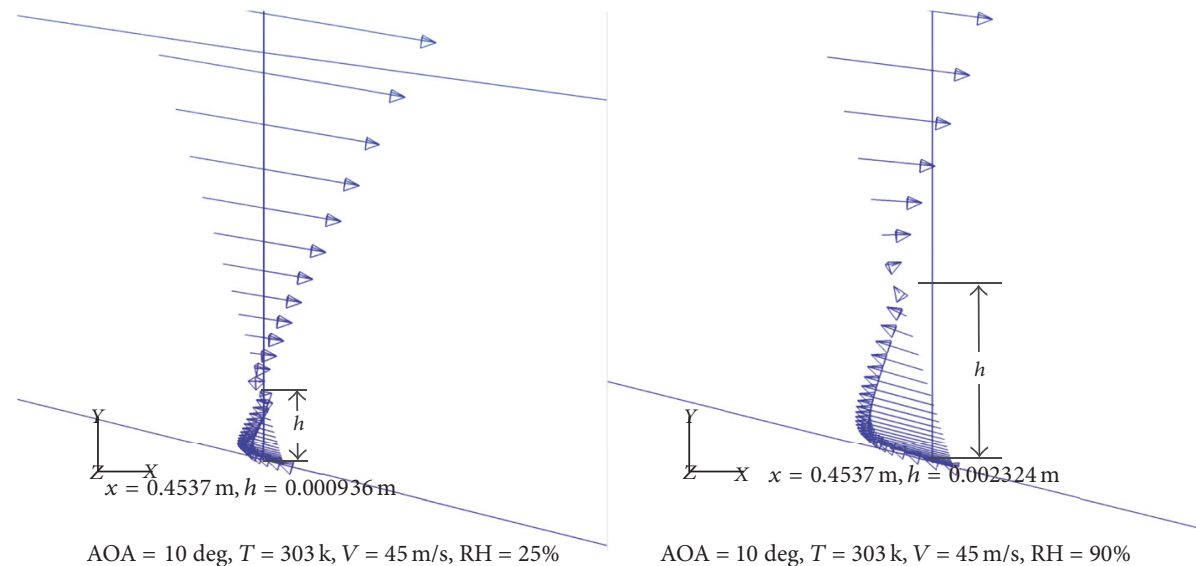

Figure 9: Vectors of air velocity for AOA $=10$ degrees (EWF model).

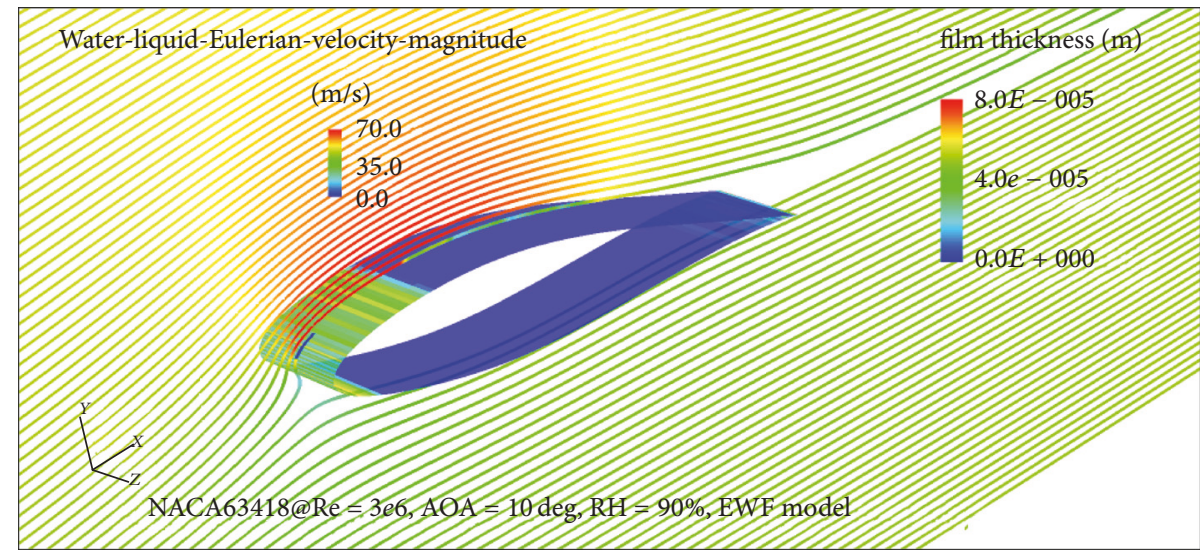

FIGURE 10: Contour plots of water film thickness around airfoil for AOA $=10$ degrees (EWF model).

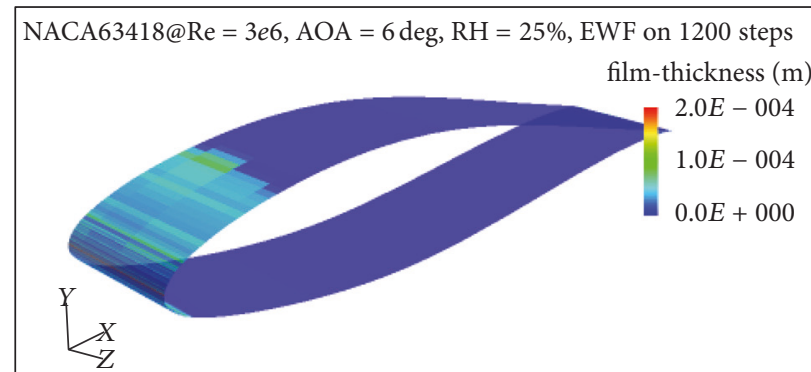

NACA63418@Re $=3 e 6, \mathrm{AOA}=6 \mathrm{deg}, \mathrm{RH}=90 \%, \mathrm{EWF}$ on 1200 steps film-thickness $(\mathrm{m})$

NACA63418@Re $=3 e 6, \mathrm{AOA}=10 \mathrm{deg}, \mathrm{RH}=25 \%$, EWF on 1200 steps

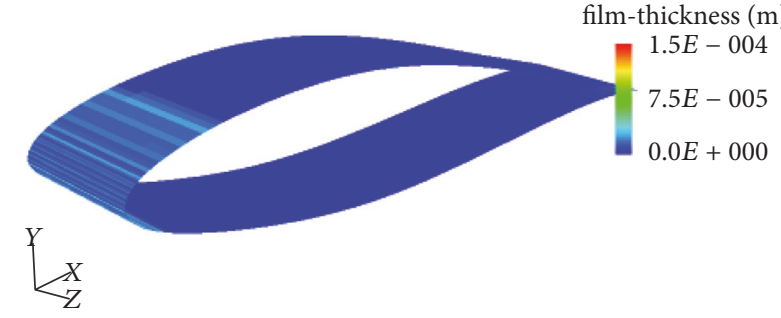

NACA63418@Re $=3 e 6, \mathrm{AOA}=10 \mathrm{deg}, \mathrm{RH}=90 \%, \mathrm{EWF}$ on 1200 steps $2.0 E-004$
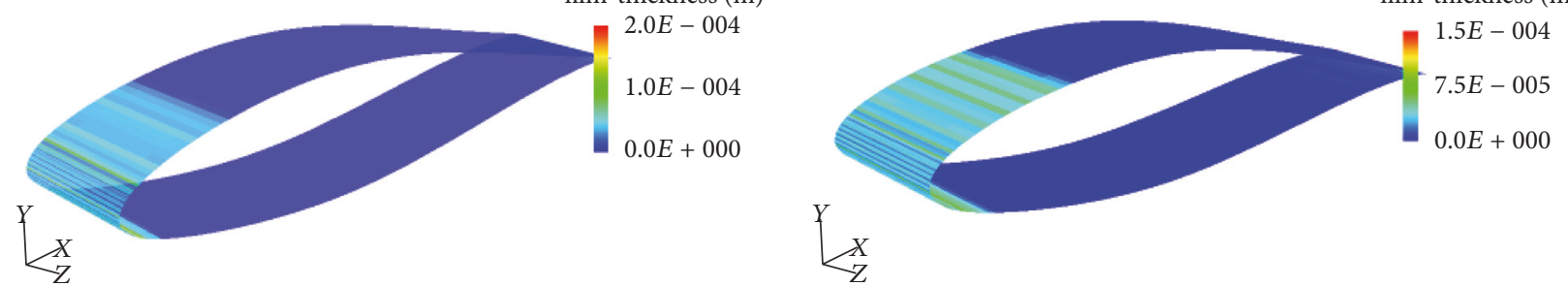

FIGURE 11: Contour plots of water film thickness on airfoil for $\mathrm{AOA}=6,10$ degrees (EWF model). 


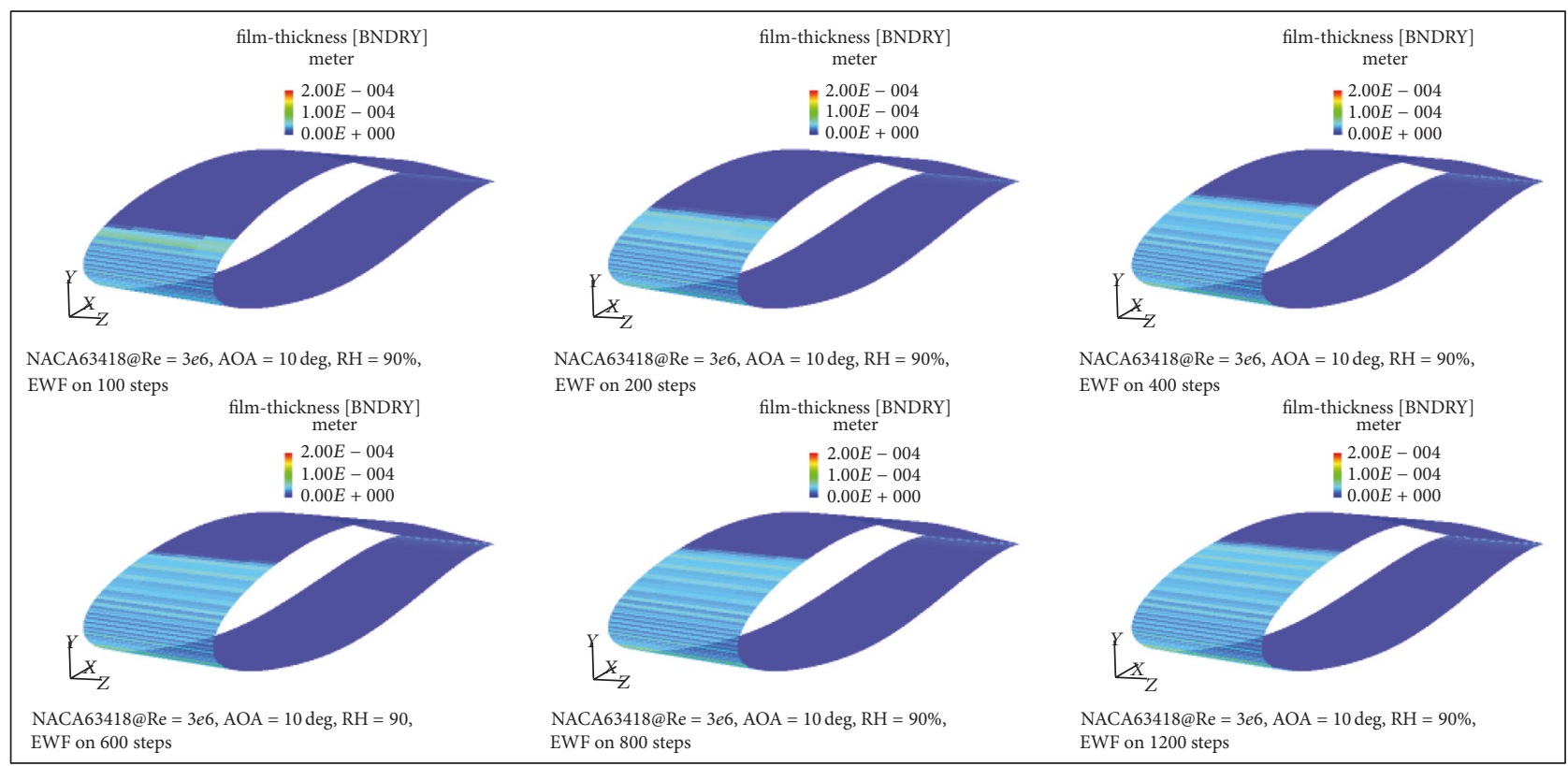

FIGURE 12: Contour plots of water film thickness with times (steps) on airfoil for AOA = 10 degrees (EWF model).

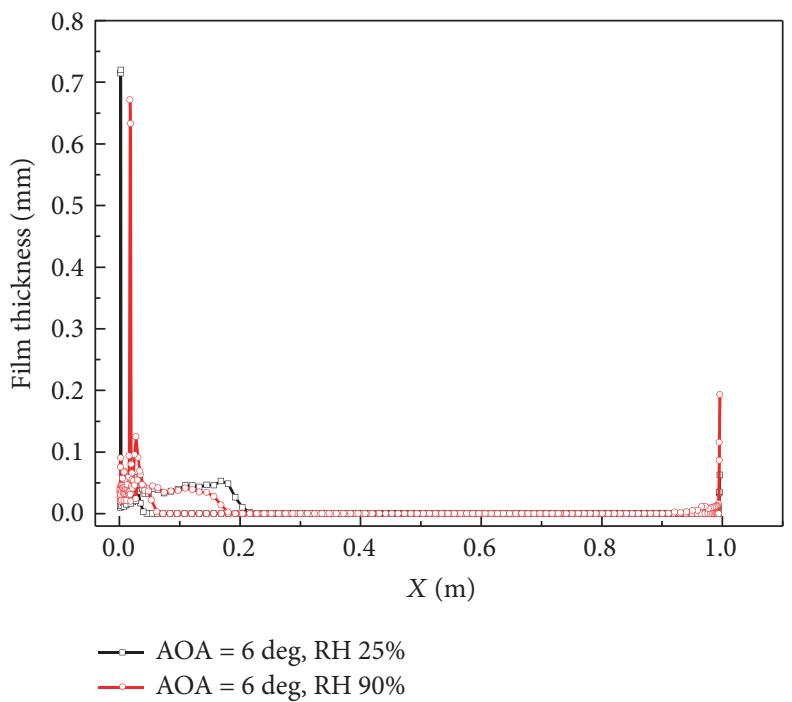

FIGURE 13: Contour plots of film thickness on airfoil for AOA $=6$ degrees (EWF model).

numerical calculation is only performed on the leaf. The spherical region of 15 times the impeller radius is chosen as the computational domain. In order to improve the calculation accuracy and computation time saving, we used full hexahedral grid. Figure 15 shows the overall outline of the grid and local amplification. Fine mesh is used in the near wake region as blade root and tip. The mesh size of the tip wake area is less than $0.05 \mathrm{~m}$, near the rotor area is less than $2.5 \mathrm{~m}$, and outside of compute domain is less than $20 \mathrm{~m}$. The total number of grids nodes is about 6.2 million. $K$ omega SST model is the most commonly used in the field of wind turbine. Table 4 shows the component transport model and film condensation model calculation of the aerodynamic parameters of the blade; it can be seen that, in the two models, with the humidity increasing, the power is reduced, and $90 \%$ relative humidity compared to the $25 \%$ relative humidity power decreases by about $1 \%$.

Table 5 summarized the result that higher humidity lower the power it generated primarily due to density effect. Figure 16 shows that the condensation mass flow rate distribution on the surface of the blade is calculated by the condensation model. Negative on behalf of condensation water, you can see that most of the area of the surface of the blade has the condensation of water, along the blade airfoil 


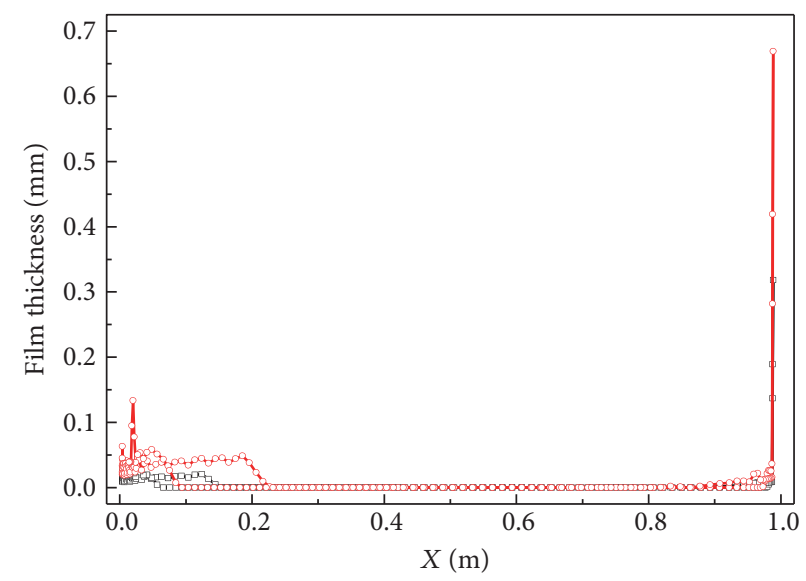

- $\mathrm{AOA}=10 \mathrm{deg}, \mathrm{RH} 25 \%$

$\longrightarrow \mathrm{AOA}=10 \mathrm{deg}, \mathrm{RH} 90 \%$

FIGURE 14: Contour plots of film thickness on airfoil for AOA $=10$ degrees (EWF model).
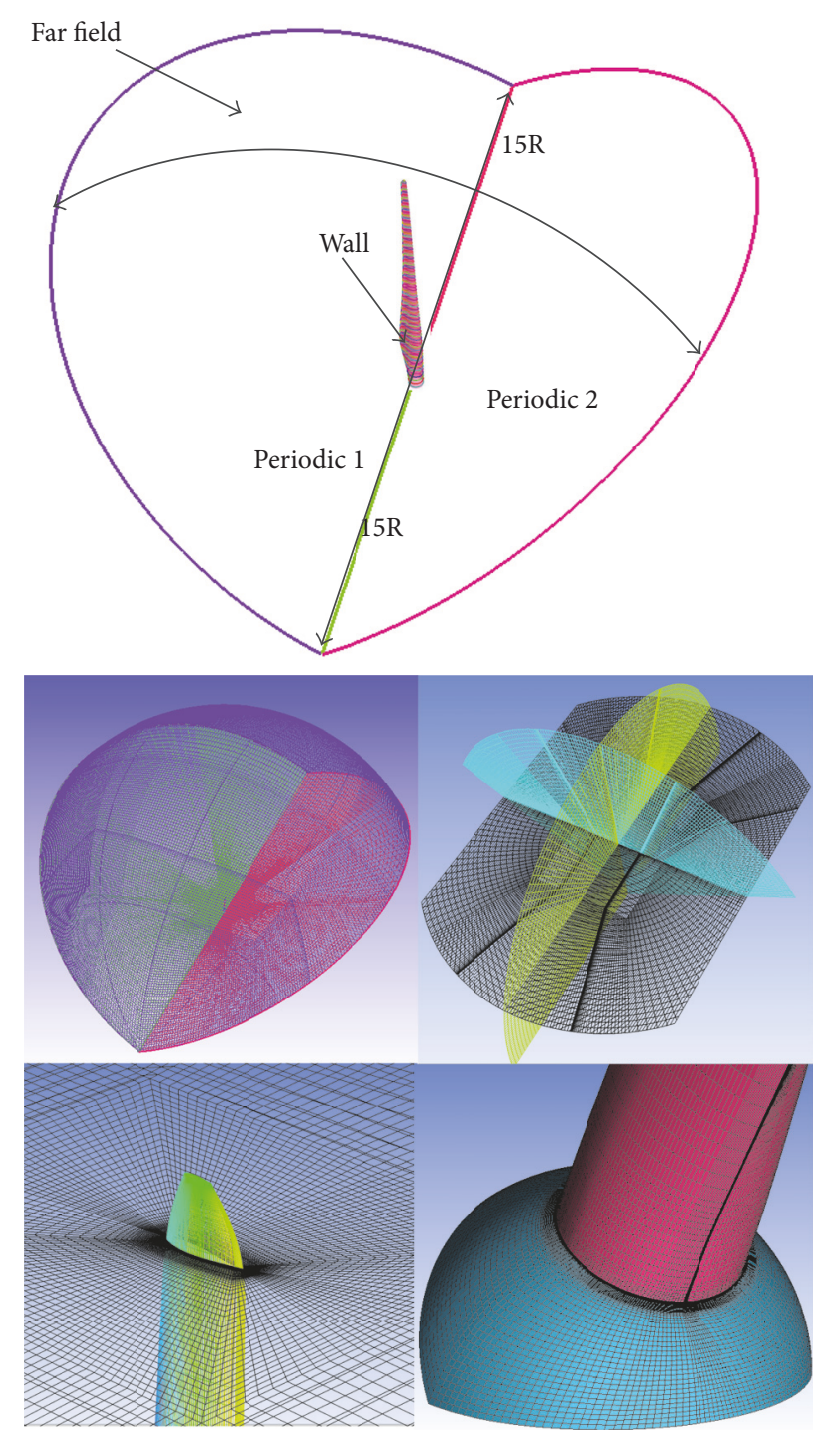

FIGURE 15: Computing domain and mesh for blade at various locations. 


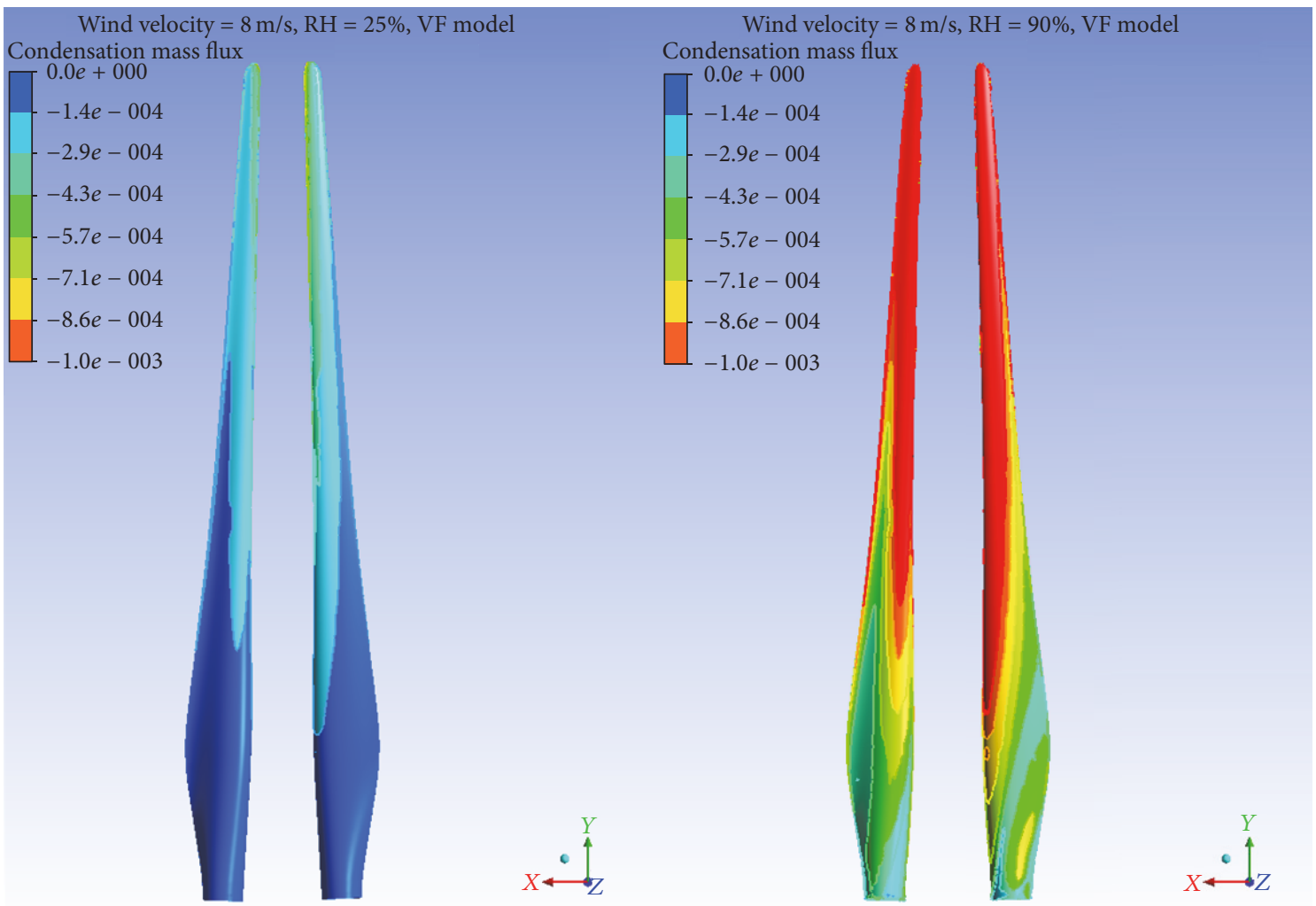

FIGURE 16: Condensation mass flux on blade surface for $V=8 \mathrm{~m} / \mathrm{s}$.

TABLE 5: Blade aerodynamic performance at velocity $=8 \mathrm{~m} / \mathrm{s}$ with species transport model and vapor film condensation model at temperature of $303 \mathrm{~K}$ degree.

\begin{tabular}{lccccc}
\hline Model & $\begin{array}{c}\text { RH } \\
(\%)\end{array}$ & $\begin{array}{c}\text { Moment- } \\
z\end{array}$ & $\begin{array}{c}\text { Power } \\
{[\mathrm{NW}]}\end{array}$ & $\begin{array}{c}\text { Moment- } \\
y \\
{[\mathrm{Nm}]}\end{array}$ & $\begin{array}{c}\text { Force- } z \\
{[\mathrm{n}]}\end{array}$ \\
\hline $\begin{array}{lccccc}\text { Species transport } \\
\text { model }\end{array}$ & 25 & 141582.3 & 738.9 & 53441.8 & 49360.7 \\
Vapor film & 90 & 140106.4 & 731.2 & 52881.2 & 48843.2 \\
condensation & 25 & 141828.5 & 740.2 & 53480.8 & 49416.3 \\
& 90 & 140345.7 & 732.4 & 52927.7 & 48912.4 \\
\hline
\end{tabular}

section direction, and the front position has maximum mass flow rate. Along the direction of the blade, the blade root to tip, the whole condensation mass flow rate increases.

4.2. Result Analysis Based on Eulerian Wall Film Model. The water volume fraction curves of blades with different section positions at $25 \%$ and $90 \%$ relative humidity are shown in Figure 17. The higher the humidity is, the higher the volume fraction of water is. Humidity is the same, from root to leaf tip, and numerical water volume fraction increases rapidly. In the inner region of the blade (near root), the water is mainly distributed in the position of the droplet impingement region and the trailing edge in suction side of the blade, and the outer side of the blade (near blade tip) is only distributed in the leading edge. Meantime, water distribution can be found clearing in Figure 18; therefore, actual environment, high humidity in cold area, and the location in winter are the most easily freeze position, and arid sandy area is the location with the most polluted areas. These locations require special protection.

\section{Conclusions}

With the background of high humidity environment, the density effect and the airfoil/blade aerodynamic performance of different humidity are simulated by using CFD Fluent with the component transport, UDF thin film condensation model, and the Eulerian Wall Film model. It is found that the high humidity has considerable effect on density at high temperature condition and little effect on airfoil/blade aerodynamic performance, and it was found that the water vapor condensation on the surface of the airfoil or a blade may occur around the leading edge and trailing of airfoil, which then leads to blade contamination in the dirty environment such as dust and insect or icing in winter and low temperature conditions. When that happens, the wind turbine performance may be severely degraded, especially for the airfoil sensitivity to the surface. In a foggy day, the study found that water droplets in the air with high humidity are impacted and collected on the airfoil surface to form a water film, which affects the flow of the boundary layer, resulting in much higher drag and thus losing good performance. The 

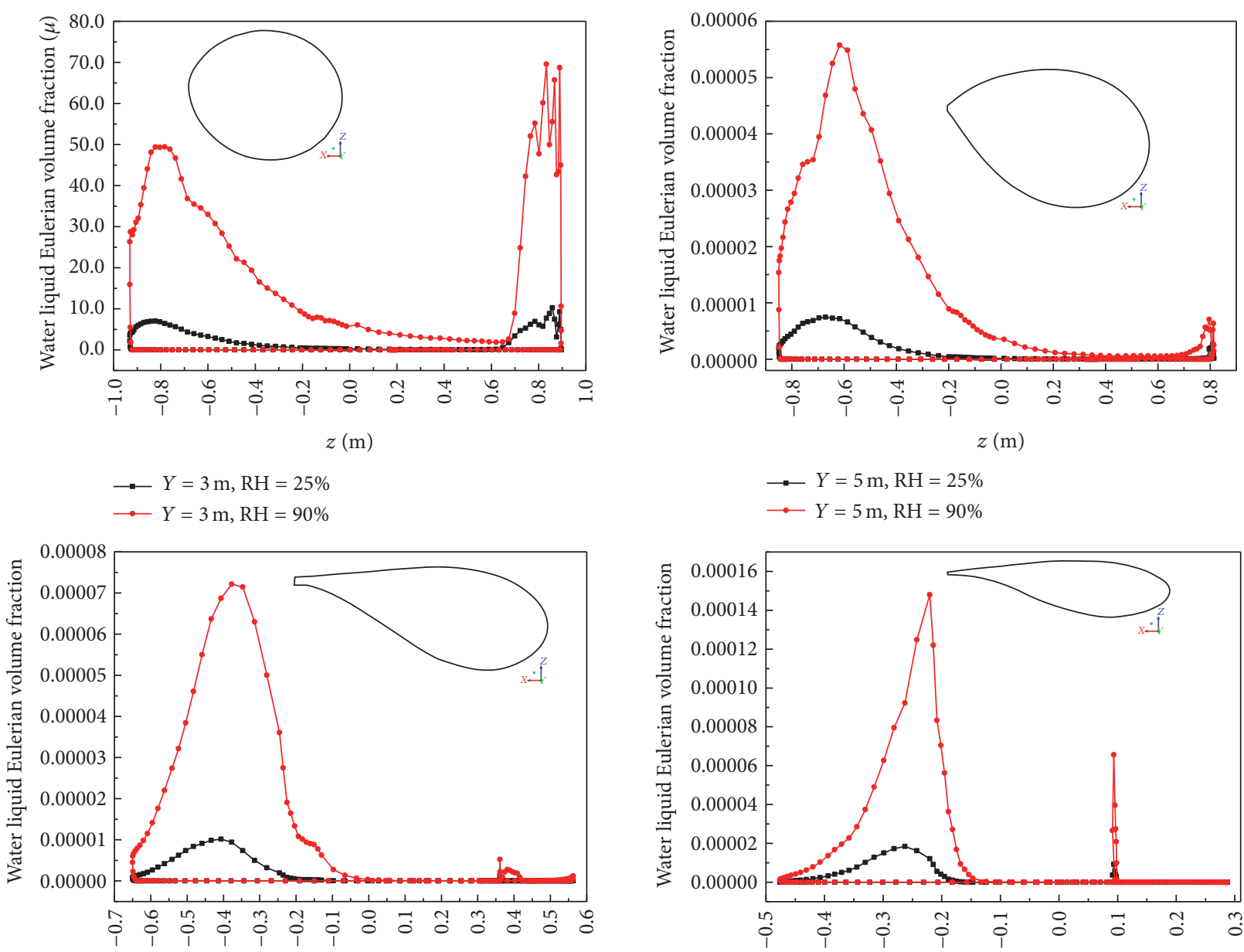

$\longrightarrow Y=5 \mathrm{~m}, \mathrm{RH}=25 \%$
$\longrightarrow Y=5 \mathrm{~m}, \mathrm{RH}=90 \%$

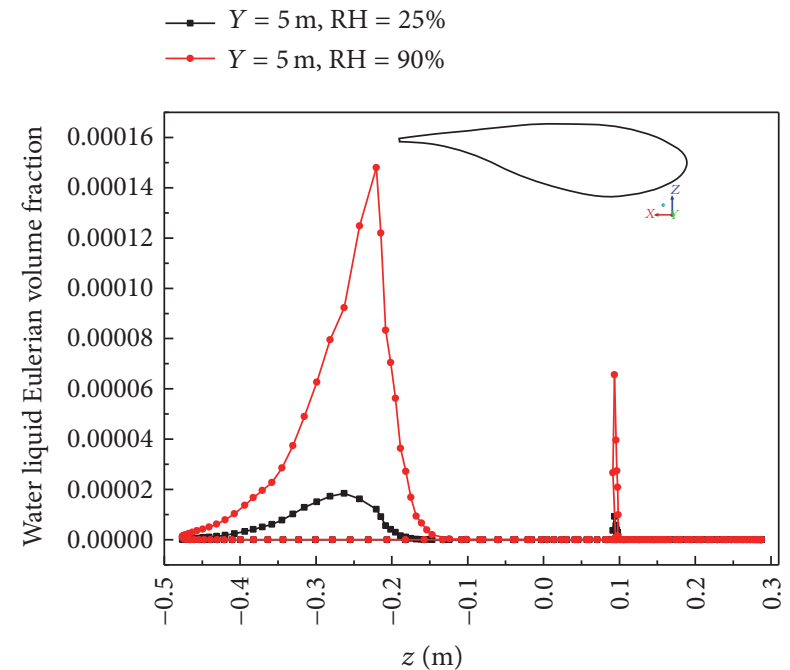

$z(\mathrm{~m})$

$\rightarrow Y=10 \mathrm{~m}, \mathrm{RH}=25 \%$

$\rightarrow Y=15 \mathrm{~m}, \mathrm{RH}=25 \%$

$\rightarrow Y=10 \mathrm{~m}, \mathrm{RH}=90 \%$

$\rightarrow Y=15 \mathrm{~m}, \mathrm{RH}=90 \%$
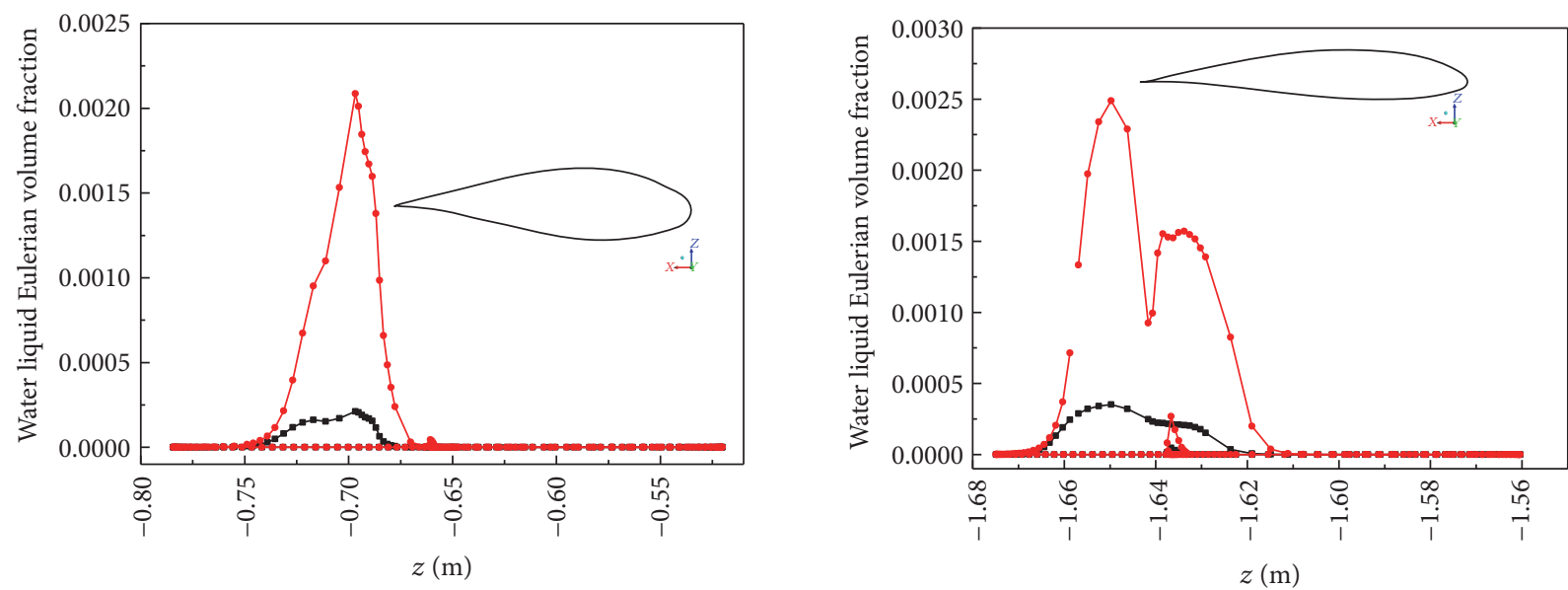

$\rightarrow Y=30 \mathrm{~m}, \mathrm{RH}=25 \%$

- $Y=40.5 \mathrm{~m}, \mathrm{RH}=25 \%$

$\rightarrow Y=40.5 \mathrm{~m}, \mathrm{RH}=90 \%$

FIGURE 17: Water volume fraction at various spanwise location for $\mathrm{RH}=25 \%$ and $90 \%$ (EWF model). 

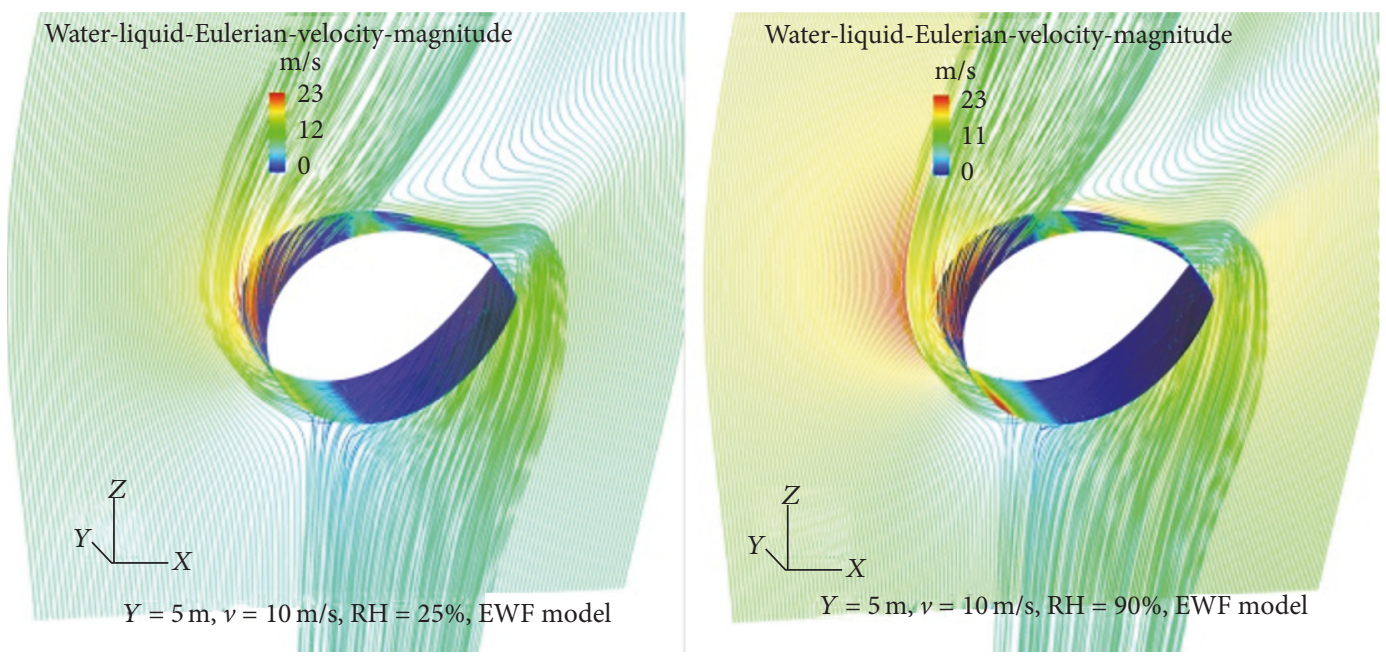

(a)
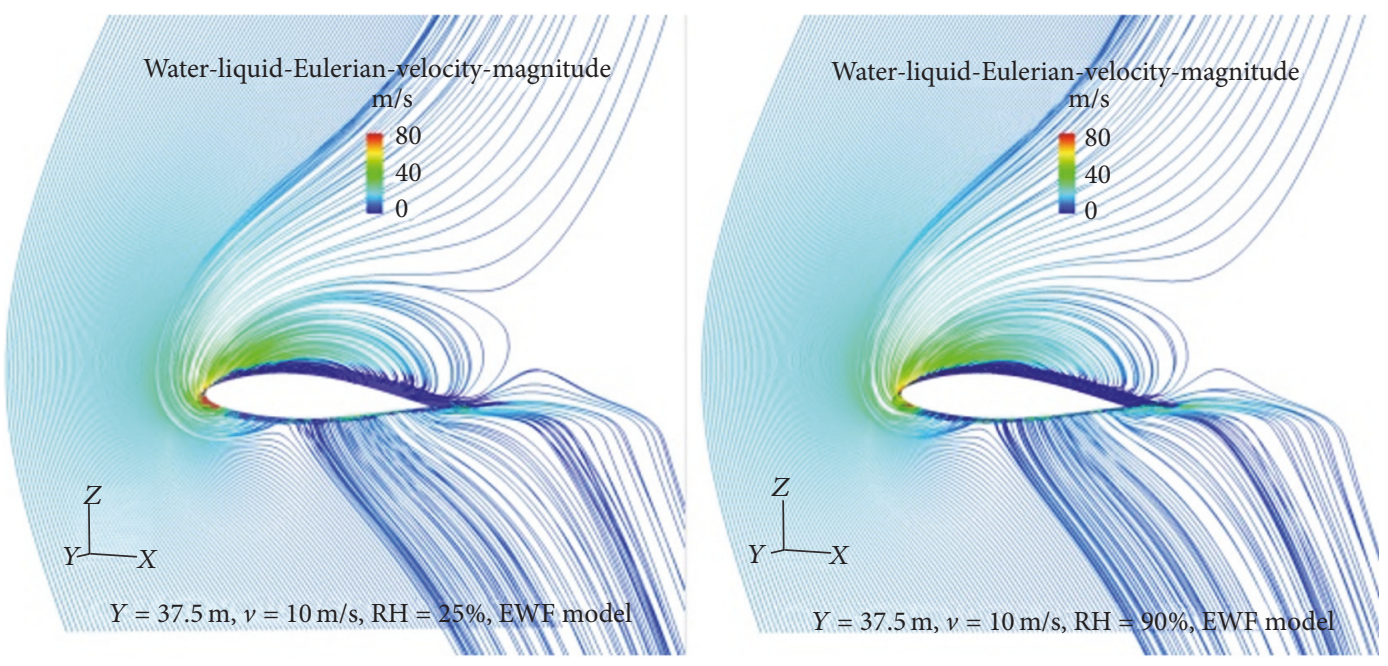

(b)

FIGURE 18: Streamline of velocity at blade clip location for (a) $Y=3.5 \mathrm{~m}$ and (b) $Y=37.5 \mathrm{~m}$.

similar behaviors were found by other studies that found the loss of performance in rainy day.

\section{Conflicts of Interest}

The authors declare that there are no conflicts of interest regarding the publication of this paper.

\section{Acknowledgments}

The authors would like to acknowledge and thank Dr. Chen Chunmei, Dr. Gao Wei, and Chief Cai Xiaofeng from China Creative Wind Energy Inc. for support and sponsorship of the project. The authors would like to thank Dr. Tang Hongfeng and Dr. Wang Hu from CDT Science and Technology Research Institute for support of this project. The authors would like to thank Professor Wang Xiaodong from
China North Electric Power University for many interesting discussions and helpful suggestions.

\section{References}

[1] A. Kumar and S. Mazumder, "Coupled solution of the species conservation equations using unstructured finite-volume method," International Journal for Numerical Methods in Fluids, vol. 64, no. 4, pp. 409-442, 2010.

[2] B. Bell, Application Brief: Film Condensation of Water Vapor, Fluent, Inc., Lebanon, NH, USA, 2003.

[3] K. Das, C. Manepally, R. Fedors, and D. Basu, Numerical and Experimental Study of In-Drift Heat and Mass Transfer Progesses, Center for Nuclear Waste Regulatory Analyses, San Antonio, Tex, USA, 2011.

[4] R. B. Bird, W. E. Stewart, and E. N. Lightfoot, Transport Phenomena, John Wiley and Sons, New York, NY, USA, 1960.

[5] ANSYS Inc, ANSYS-FLUENT ${ }^{\circledR}$ Version 12.1 User's Guide, ANSYS, Inc, Canonsburg, Pa, USA, 2009. 
[6] D. K. Kolmogorov, W. Z. Shen, N. N. Sørensen, and J. N. Sørensen, "Fully consistent CFD methods for incompressible flow computations," Journal of Physics: Conference Series, vol. 524, no. 1, Article ID 012128, 2014.

[7] E. C. Douvi and D. P. Margaris, "Aerodynamic performance investigation under the influence of heavy rain of a NACA 0012 airfoil for wind turbine applications," International Review of Mechanical Engineering, vol. 6, no. 6, pp. 1228-1235, 2012.

[8] M. Cai, E. Abbasi, and H. Arastoopour, "Analysis of the performance of a wind-turbine airfoil under heavy-rain conditions using a multiphase computational fluid dynamics approach," Industrial and Engineering Chemistry Research, vol. 52, no. 9, pp. 3266-3275, 2013.

[9] A. C. Cohan and H. Arastoopour, "Numerical simulation and analysis of the effect of rain and surface property on windturbine airfoil performance," International Journal of Multiphase Flow, vol. 81, pp. 46-53, 2016.

[10] Z. Wu and Y. Cao, "Numerical simulation of flow over an airfoil in heavy rain via a two-way coupled Eulerian-Lagrangian approach," International Journal of Multiphase Flow, vol. 69, pp. 81-92, 2015.

[11] “Converter for humidity of air," http://www.cactus2000.de/uk/ unit/masshum.shtml.

[12] W. C. Reynolds, Thermodynamic Properties in SI, 1979.

[13] N. Harper, "Detecting Ice on Wind-turbine Blade," 2011, http:// www.windpowerengineering.com/maintenance/detecting-iceon-wind-turbine-blades/.

[14] M. Wadham-Gagnon, C. Farley, and C. Arbez, "Wind site considerations: in cold climate conditions," 2013, http://www .nacleanenergy.com/articles/16824/wind-site-considerations-incold-climate-conditions.

[15] L. Rempel, "Rotor blade leading edge erosion-real life experiences," Wind Systems Magazine, pp. 22-24, 2012.

[16] C. J. Spruce, "Power performance of active stall wind turbines with blade contamination," in Proceedings of the European Wind Energy Conference, Athens, Greece, 2006. 


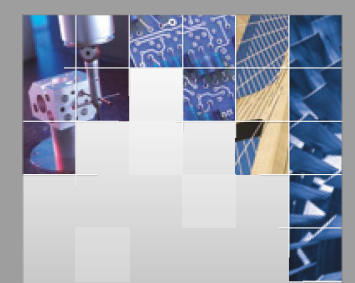

\section{Enfincering}
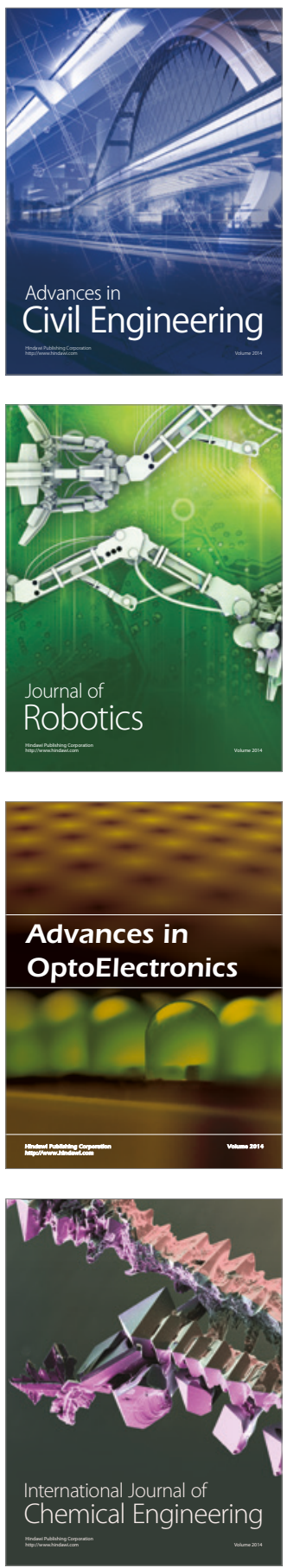

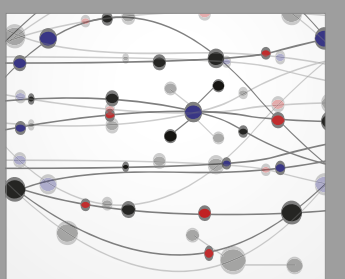

The Scientific World Journal

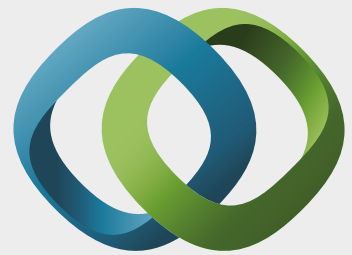

\section{Hindawi}

Submit your manuscripts at

https://www.hindawi.com
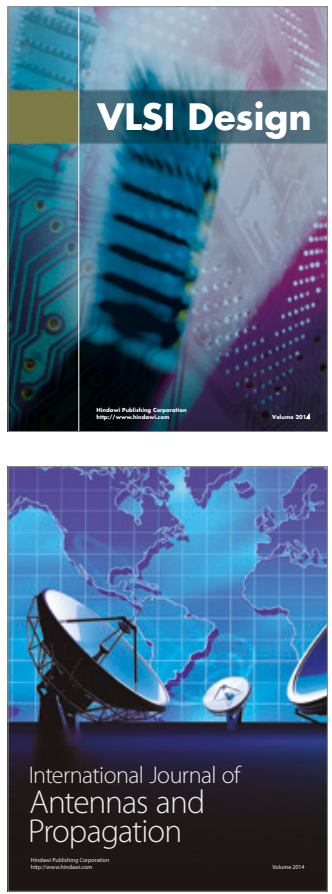

\section{Rotating}

Machinery
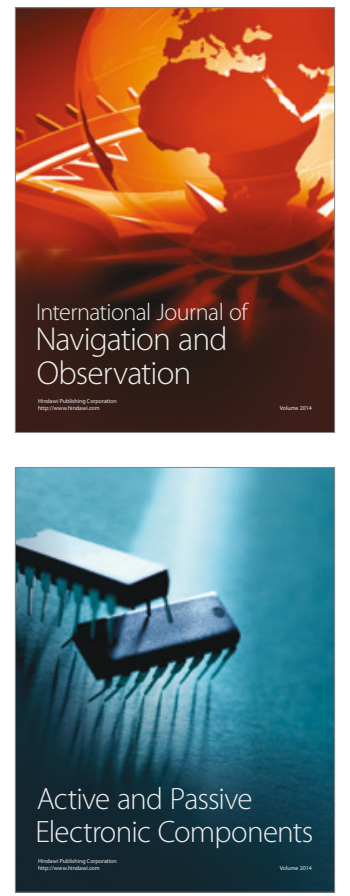
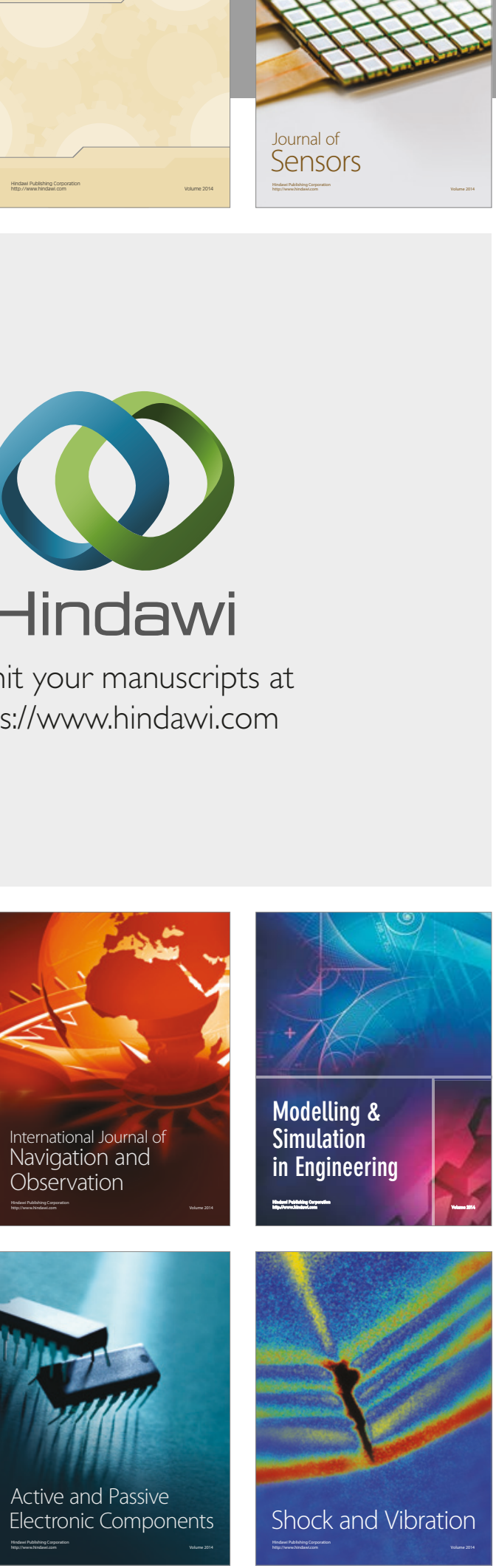
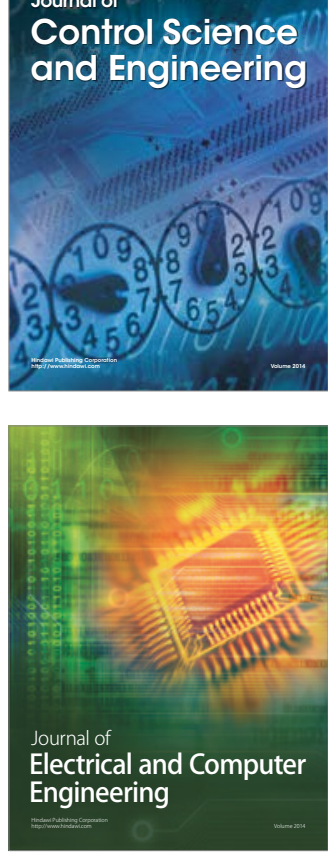

Distributed

Journal of

Control Science

and Engineering
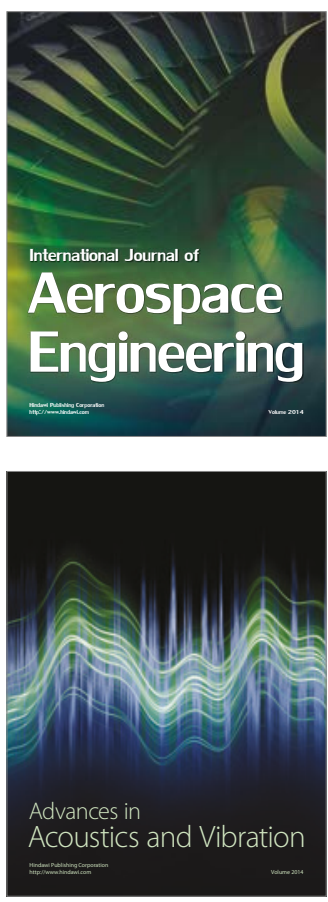

Sensor Networks 